\title{
Biomimicry inspired Adaptive Building Envelope in hot climate
}

\author{
Sahar Mohamed Abd El-Rahman ${ }^{\text {a }}$, Sobhy Ibrahim Esmail ${ }^{\text {b }}$, Husam Bakr Khalil ${ }^{\mathrm{c}}$, Zeinab \\ El-Razaz ${ }^{\text {d }}$ \\ ${ }^{a}$ Ph.D. Student , Architecture Department, Faculty of Engineering Mattaria , Helwan University. Teaching Assistant at Modern \\ Academy. \\ ${ }^{\mathrm{b}} \mathrm{Ph} . \mathrm{D}$. Student, Teaching Assistant, Architecture Department, Faculty of Engineering Mattaria, Helwan University. \\ ${ }^{c}$ Professor of Architecture, Architecture Department, Faculty of Engineering, The British University in Egypt (BUE). \\ ${ }^{d}$ Professor of Architecture, Architecture Department, Faculty of Engineering Mattaria, Helwan University .
}

\begin{abstract}
Adaptation strategies and principles can be learned from nature. It has developed through their evolution various strategies to cope with the different climatic aspects that suit different environmental conditions. Investigating and analyzing these strategies and their dominating principles is essential prior to the transfer of their strategies to adaptive building envelopes. From plant adaptations to Building envelopes using biomimicry. This approach can help future building skins to be more responsive and adaptive that change with time to adapt environmental conditions to both external and internal conditions and satisfies thermal comfort levels.
\end{abstract}

Keywords: Biomimicry - Adaptive Building Envelopes - Energy efficiency - Plant adaptations - Building react with Climate change.

\section{Research problem}

Currently, the existing buildings in the Egyptian context have poor building envelope; the buildings are not efficiently 'sealed' and are liable to the loss and gain of heat more aggressively. This is translated in poor energy performance, where higher amounts of energy are needed to maintain thermal comfort and compensate for this leaking.

\section{Introduction}

Buildings represent a great environmental challenge, as they are globally responsible for approximately $23 \%$ of the entire global primary energy usage and $30 \%$ of the entire global electricity consumption [1].About, $60 \%$ of the total consumed energy in buildings is dedicated to space heating and cooling [2].

The building envelope plays the main role in controlling energy consumption in buildings and maintains internal comfort [3], [4]. Conventionally, a building envelope has been considered a thermal barrier to prevent heat loss or shade to control solar gain [5] , [6] . In fact, most of the building envelopes are constructed to provide static design solutions [7]. Ali et al. [8] stated that conventional solutions for building envelopes lack the ability to adapt to contextual issues and needs.

Nature has much to teach us as architects. Natural world is ever changing. As far as weather adaptability is concerned, plants and animals have various ingenious adapting capabilities. So in our quest to create a more sustainable built environment, it makes sense to learn from natural organisms and to mimic useful relevant treatments in order to create more sustainable and energy efficient buildings [9]. 


\section{Defining Biomimicry}

The term biomimicry was derived from the Greek bios, which means life or nature, and mimesis, which means imitation; 'imitating nature' [10].

Biomimicry has many definitions. Lipholt (2019), defined biomimicry as "an approach to innovation that seeks sustainable solutions to human challenges by emulating nature's time-tested patterns and strategies" [11] A According to Baumeister et. al., 2012, Biomimicry is the examination of nature, its models, processes, systems, and elements to emulate or take inspiration from to solve human problems. Another definition by Scott \& Vare (2012) is that Biomimicry is the science of copying natural systems and designs, to create new industrial products. It is based on what we can learn from the nature, not on what we can extract from it [12].

The biomimicry principles focus exclusively on nature's attributes. The biomimicry principles focus exclusively on nature's attributes; there by implying that humans have much to learn from the billions of years of the natural worlds evolutionary experience. They are: [13] they are important checklists to be adhered to in ensuring the application of biomimicry resulting in sustainable outcomes. According to the Biomimciry Group, the six (6) major principles of biomimicry and their constituting twenty-three (23) principles are: [14]

Table (1). The major principles of Biomimicry. ${ }^{(B y}$ The Researcher)

\begin{tabular}{|c|c|c|}
\hline Principles & Description & Secondary Principles \\
\hline \multirow{4}{*}{$\begin{array}{c}\text { Resource } \\
\text { (material } \\
\text { and } \\
\text { energy) } \\
\text { efficient }\end{array}$} & \multirow{4}{*}{$\begin{array}{l}\text { This is skilfully and } \\
\text { conservatively taking } \\
\text { advantage of resources and } \\
\text { opportunities. }\end{array}$} & using multifunctional design \\
\hline & & $\begin{array}{l}\text { using low energy processes (minimise energy consumption } \\
\text { by reducing requisite temperatures, pressures, and/or time } \\
\text { for reactions) }\end{array}$ \\
\hline & & recycling all materials \\
\hline & & $\begin{array}{l}\text { Fitting form to function (select shape or pattern based on } \\
\text { need). }\end{array}$ \\
\hline \multirow{3}{*}{$\begin{array}{c}\text { Evolve to } \\
\text { survive }\end{array}$} & \multirow{3}{*}{$\begin{array}{l}\text { This is the continuous } \\
\text { incorporation and } \\
\text { embodying of information to } \\
\text { ensure enduring } \\
\text { performance. }\end{array}$} & $\begin{array}{l}\text { replicating strategies that work (repeat successful } \\
\text { approaches) }\end{array}$ \\
\hline & & $\begin{array}{l}\text { integrating the unexpected (incorporate mistakes in ways } \\
\text { that can lead to new forms and functions) }\end{array}$ \\
\hline & & Exchange and alter information to create new options. \\
\hline \multirow{5}{*}{$\begin{array}{l}\text { Adapt to } \\
\text { changing } \\
\text { conditions }\end{array}$} & \multirow{5}{*}{$\begin{array}{l}\text { This is appropriately } \\
\text { responding to dynamic } \\
\text { contexts }\end{array}$} & maintaining integrity through self-renewal \\
\hline & & embodying resilience through variation \\
\hline & & redundancy \\
\hline & & decentralisation \\
\hline & & incorporating diversity \\
\hline \multirow{3}{*}{$\begin{array}{l}\text { Integrate } \\
\text { developm } \\
\text { ent with } \\
\text { growth }\end{array}$} & \multirow{3}{*}{$\begin{array}{l}\text { This entails optimally } \\
\text { investing and engaging in } \\
\text { strategies that promote both } \\
\text { development and growth. }\end{array}$} & combining modular and nested components \\
\hline & & building from the bottom up \\
\hline & & self-organising \\
\hline \multirow{5}{*}{$\begin{array}{l}\text { Been locally } \\
\text { attuned and } \\
\text { responsive }\end{array}$} & \multirow{5}{*}{$\begin{array}{l}\text { This is fitting into and } \\
\text { integrating with the } \\
\text { surrounding environment. }\end{array}$} & using readily available materials \\
\hline & & Use of solar/renewable energy. \\
\hline & & cultivating cooperative relationships \\
\hline & & leveraging cyclic processes \\
\hline & & using feedback loops \\
\hline \multirow{3}{*}{$\begin{array}{l}\text { Using life- } \\
\text { friendly } \\
\text { chemistry }\end{array}$} & \multirow{3}{*}{$\begin{array}{l}\text { This entails the use of } \\
\text { chemistry that supports life } \\
\text { processes. }\end{array}$} & building selectively with a small subset of elements \\
\hline & & breaking down products into benign constituents \\
\hline & & Doing chemistry in water (use water as solvent). \\
\hline
\end{tabular}


Biomimicry can be categorized into three levels: (1) form, (2) process and (3) ecosystem [15]. Benyus [16] stated that mimicking practice undergoes three levels. The first stage is to copy the attributes of an organism, namely, appearance, visual shape, components, materials and morphological features. In other words, it means duplication of an organism's design. The second stage is to look deeper into reproducing a biological entity's procedures within its medium to mimic the natural processes. The third stage involves a more complicated set of processes: both form and processes of an ecosystem are duplicated.

Three levels of Biomimicry determine which aspect of 'bio' can be 'mimicked' and applied to a design problem: the organism, the behavior and the ecosystem level repeated. Within each of these levels, a further five possible mimic dimensions exist [17].

1) The design may be Biomimetic in terms of what it looks like (Form).

2) What it is made out of (Material).

3) How it is made (Construction).

4) How it works (Process).

5) What it is able to do (Function).

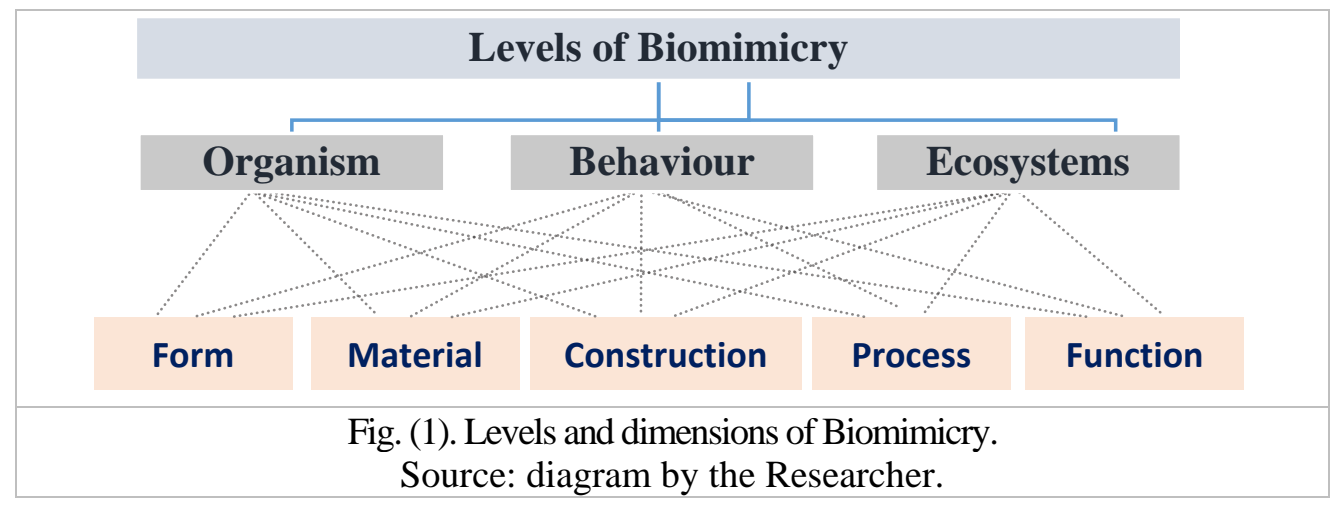

In the field of architecture, one can see many examples that is influenced by nature. Constructions similar to branches of a tree, analogies of flowers, network configurations, etc. inspired the architectural design thinking since the ancient times. This inspiration can be observed in two ways; (1) to reproduce the form with the concern of form finding, (2) or to transfer the process of emergence of a living entity (like material, form, structure, etc.) to design thinking. As it is just a concern of form finding and most of the time does not refer to a functional and an ecological approach. The second way is a different approach though, which offers to observe and understand the functionality and harmony within the nature.

It is important to understand how each living organism has its own functionality to create a nest to survive in its environment, to endure its conditions but performing this with harmony and causing no harm to its environment. These nests are built with instinct, as lightweight, stable, energy efficient dwelling based on a genetic knowledge. Emergence of these natural forms inspired architects and designers to study and research the field of biology and ecology to harness the nature's way of construction in a global network of harmony, with the objective of creating a sustainable and an ecological built environment. Examples may vary; like the material of a seashell or spider web's endurance, geometries and spatial relations 
in a beehive, photosynthesis' to harness energy from sun, etc. These examples all point out the wisdom behind nature [18].

As architects, we can benefit from biomimicry to make buildings better by pushing for more natural, integrated, efficient and healthy solutions. Perhaps this is a way for buildings to harmonize with nature in renewed ways making built environments more environmentally sound and healthy for occupants.

\section{Adaptive Building Envelopes}

Adaptive architecture as a concept has been given several alternative names, such as interactive [19],dynamic [20], kinetic [21], and Climate Adaptive Building Shells (CABS) [22], and responsive [23], are examples of these systems, that when applied to a building skin, it can actively adapt its behavior over time in response to varying environmental conditions and performance requirements. Adaptive building skins can contribute to reducing the energy demand for lighting and space conditioning, positive enrichment of indoor air quality and thermal and visual comfort levels [24] .

The building envelope represents the interface between the exterior environmental factors and the interior demands of the occupants [25].

An adaptive building envelope should respond to changing environmental impacts occurring in the exterior environs while managing indoor climate. The concept of adaptive building envelopes aims at reduced energy consumption and increased occupant comfort and control [26].

Adaptation of living organisms to their environment occurs in three main ways: morphological, a physiological and behavioral. Following these types of adaptation solutions are explained through plants [27].

Morphological or structural: Relating to an organism's shape, size, pattern or structure dependent on their particular environment, and enables better functionality for survival.

Physiological or functional: relating to an organism's chemical processes. An organismic or systemic response of an individual to a specific external stimulus in order to maintain homeostasis.

Behavioral: relating to how an organism acts. The actions organisms take for survival. This type of adaptation is linked to a signal feedback system of signal and response, where behavior marks an interaction between the organism and its environment.

\section{Methodology of Research}

This paper focuses on adaptations of plants to environment. Plants, because of their immobility have special means of protection against changing environmental conditions (e.g. darkness, light, humidity, rainwater, fire, temperature, freezing, air movement or air quality).

The methodology proposed in this study employed computational and building simulation tools (BPS) for modelling, generating and simulating a broad range of 
Biomimicry solutions, by a parametric modelling software called "Grasshopper" in Rhino, ladybug \& Honeybee plugins [28].

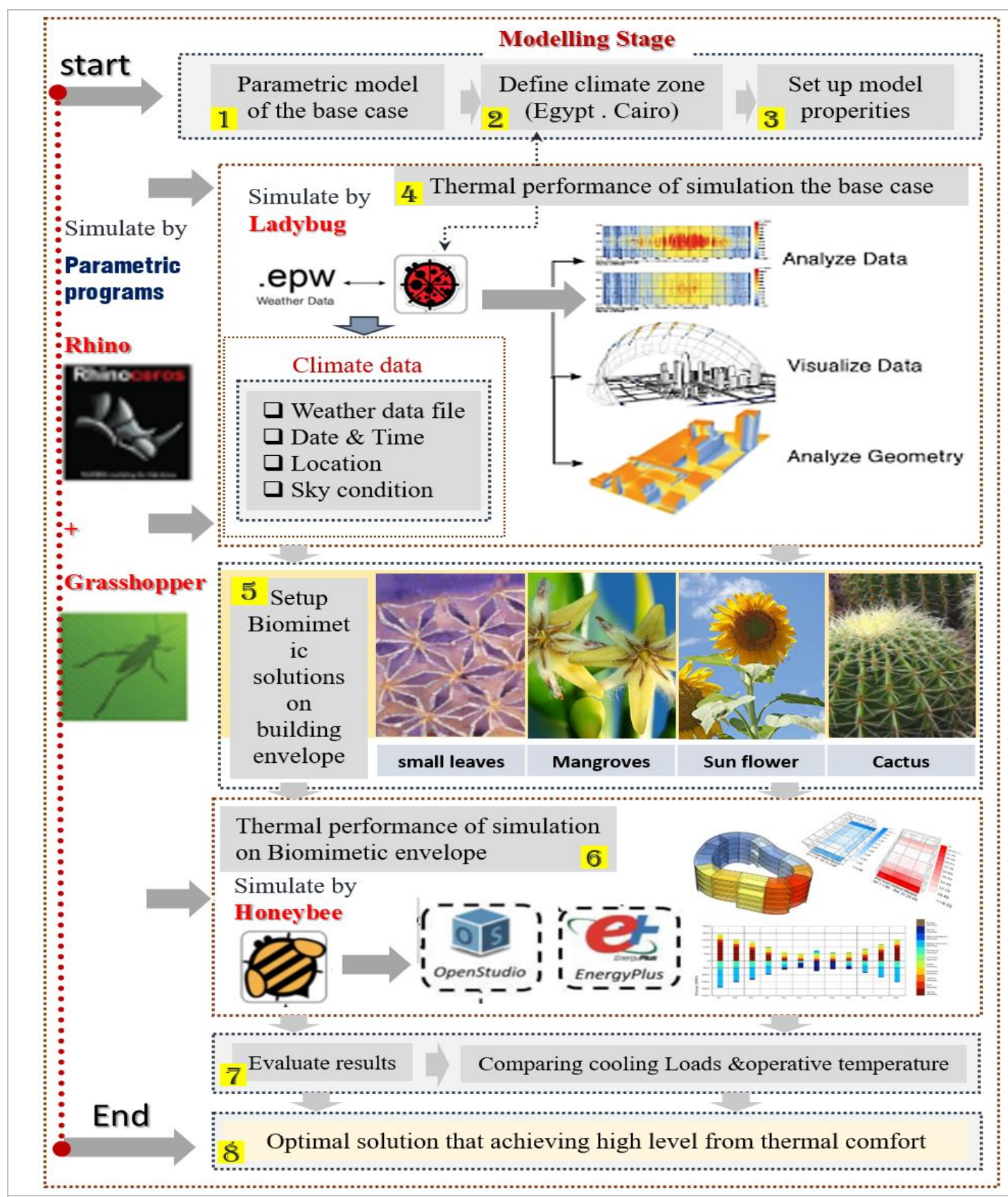

Fig.(2). Research Methodology of simulation to generate an environmentally conscious model . Source: the Researcher .

\section{Simulation of the case study}

For the exploration stage, an open source environmental plugins for Grasshopper 3D called Ladybug was used to help in creating a conscious regarding the environmental architectural design. Ladybug imports standard Energy plus Weather files (EPW) into Grasshopper and affords a variety of 3D interactive graphics to aid the decision-making process during the early design stage. Thus, the 
main objective of this stage was to understand the thermal performance at all the examined times and its interaction with the designed system using interactive visualization for sun rays tracing [29].

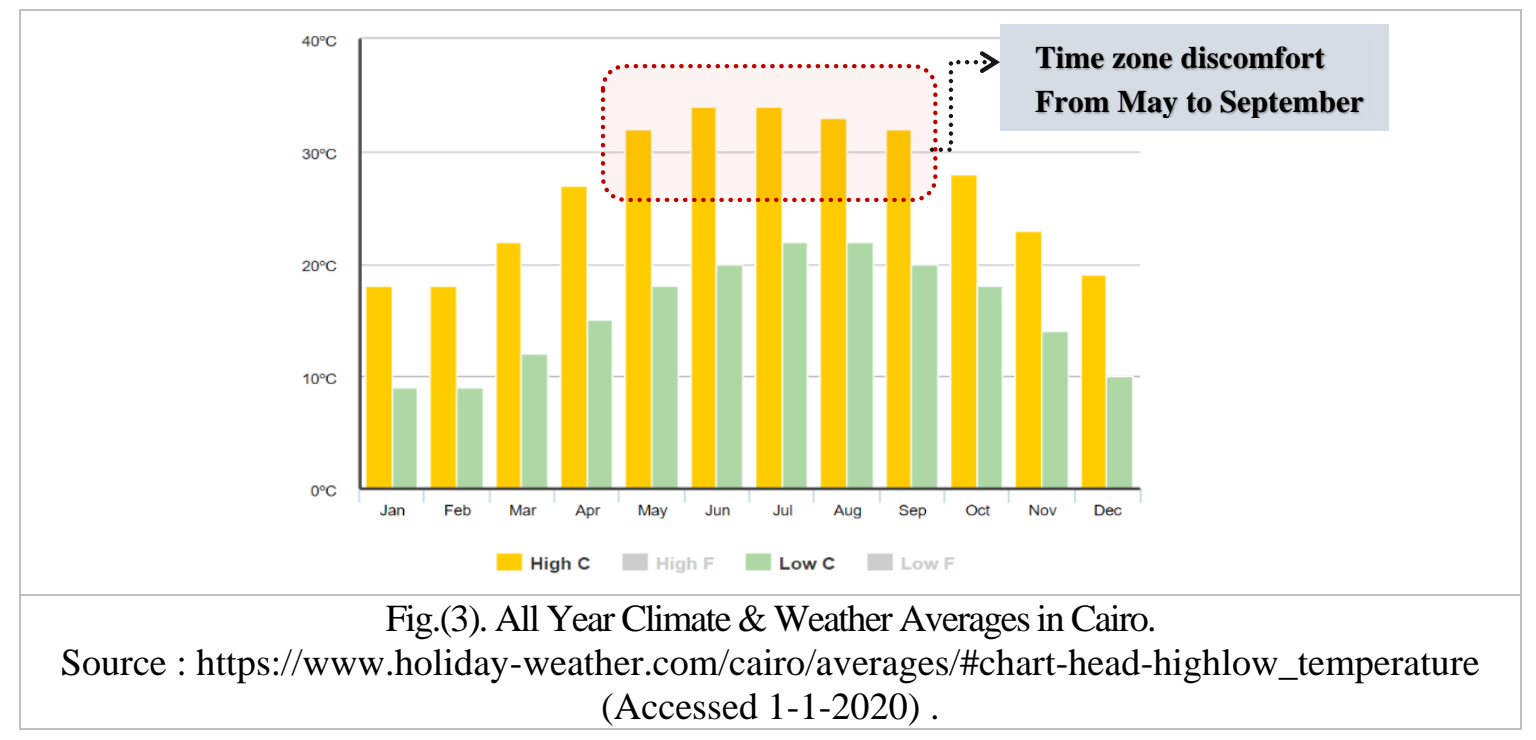

The climate in Cairo is a hot arid climate. There is virtually no rainfall during the year [30].

\section{Thermal performance of simulation the base case}

The simulation is performed using Energy Plus, which is a building thermal performance simulation software. Simulation was performed on a sub-hourly level. The features of Energy Plus make it ideal for this and other studies to assess thermal comfort in building [31]. As it is based on an essential heat balance procedure where surface temperatures are a part of the solution, the radiant effect of surfaces on thermal comfort can be addressed. Without knowledge of the inside surface temperatures, thermal comfort calculations are not possible [32].

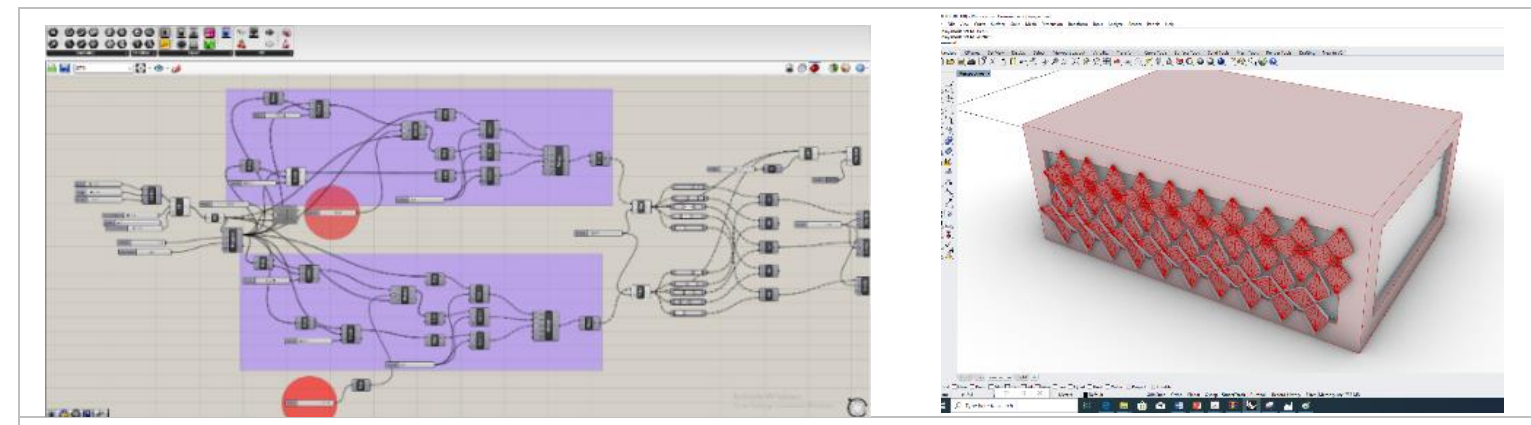

Fig. (4). Set up model in Grasshopper to evaluate biomimetic envelope for saving energy for cooling. Source: by Researcher.

Thermal comfort is defined by ASHRAE [33] as "that condition of mind which expresses satisfaction with the thermal environment". Local climate greatly affects the indoor thermal environment in buildings [34]. In hot climates, buildings are overheated during the day due to solar heat gain through the building envelope and solar penetration through windows. 
A study has shown that in Cairo, a comfortable indoor ambient temperature should be in the range of $25.5^{\circ} \mathrm{C}$ to $27^{\circ} \mathrm{C}$ for normal clothing. Humidity of the air should be in the range of $30 \%$ to $60 \%$ and the optimum air movement in the range $0.3 \mathrm{~m} / \mathrm{s}$ to $0.5 \mathrm{~m} / \mathrm{s}$ depending on occupant activity (for a naturally ventilated environment) [35].

As a result of, a simulation was applied to get values of indoor air temperature within day and outside air temperature of Cairo climate zone through the year.

\section{Energy consumption in the base case:}

It is observed in Fig (5) that energy consumption increases in May, June, July, August, September, and October due to increasing solar radiation in these months. The total yearly energy consumed by the base case model, is $31162 \mathrm{kWh} / \mathrm{y}$, indicating that the energy consumption in summer period is the highest consumption of energy.

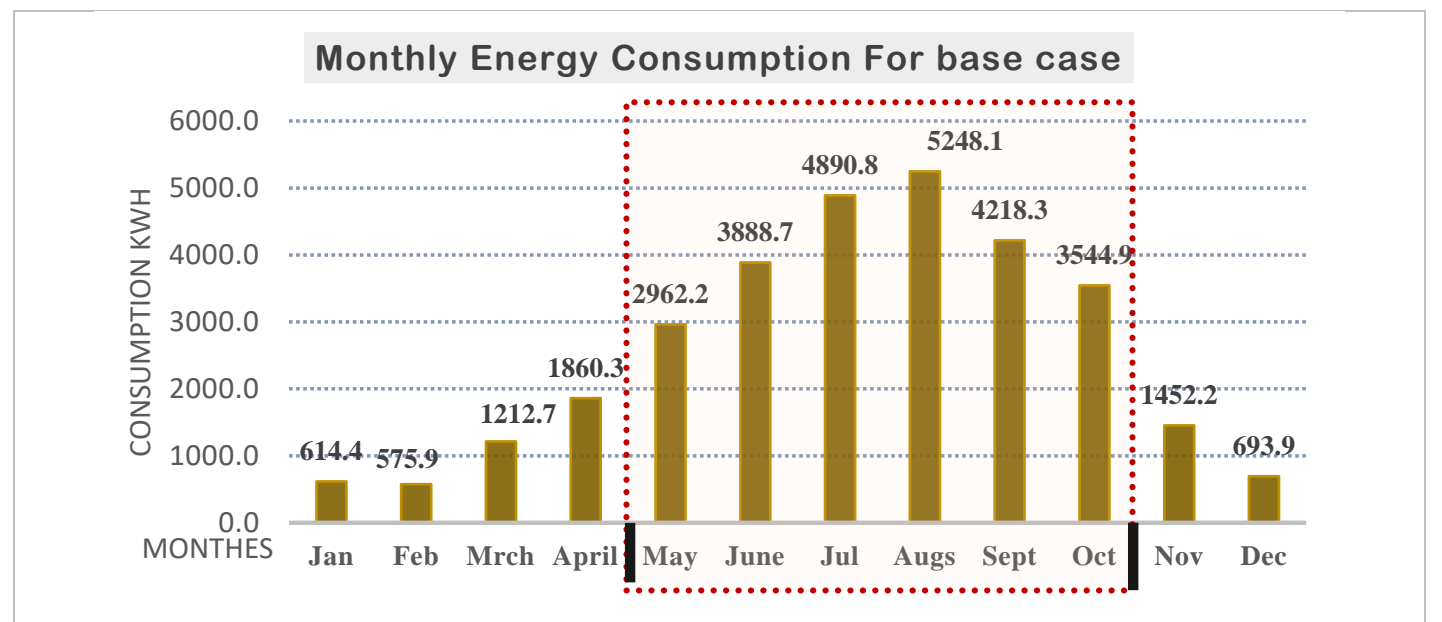

Fig. (5). The base case simulation results that show Monthly Energy Consumption for base case and maximum energy consumption during May to October (cooling period).

Source: Simulation by the researcher (Accessed 21-4-2020).

\section{Calculating the overheating zone of the base case}

For the thermal comfort part, to calculate the overheating zone we adopted the adaptive comfort in ASHRAE 55-2010 intended for offices, where the comfort limit is between $22.9^{\circ}-26.9^{\circ}[36]$.

After analysis by using ladybug \& honeybee simulation programs, the results obtained, showed that the overheating period begin from April to October which covers all the hour working from 8 am to $17 \mathrm{pm}$.

Table (2) illustrate the overheating period for the Base case. (By researcher by Honeybee thermal simulation).

\begin{tabular}{|c|c|c|c|c|c|c|c|c|c|c|c|c|}
\hline \multicolumn{10}{|c|}{ Operative temp } \\
\hline $\mathbf{H}$ & Jan & Feb & mar & April & May & Jun & July & Aug & Sep & Oct & Nov & Des \\
\hline $\mathbf{8}$ & 18.8 & 19.8 & 20.7 & 22 & 28.2 & 27.6 & 25.6 & 27.1 & 26.9 & 25.5 & 21.1 & 20.4 \\
\hline $\mathbf{9}$ & 19.1 & 20.2 & 21.9 & 22.7 & 28.5 & 27.8 & 25.8 & 27.6 & 27.3 & 26.6 & 22.8 & 22 \\
\hline $\mathbf{1 0}$ & 20.2 & 21.7 & 23.7 & 24.2 & 28.8 & 28.2 & 26.1 & 28.4 & 28.1 & 27.9 & 24.7 & 23.7 \\
\hline $\mathbf{1 1}$ & 22.7 & 24.3 & 25 & 26.2 & 29.3 & 28.7 & 26.6 & 29.1 & 29 & 29 & 27 & 24.8 \\
\hline $\mathbf{1 2}$ & 24.1 & 25.7 & 26.2 & 27.5 & 29.7 & 29.2 & 27.2 & 29.9 & 29.8 & 30.1 & 28.2 & 25.8 \\
\hline $\mathbf{1 3}$ & 25.0 & 26.4 & 26.9 & 28.1 & 30.1 & 29.6 & 27.7 & 30.5 & 30.4 & 31 & 28.9 & 26.5 \\
\hline
\end{tabular}




\begin{tabular}{|c|c|c|c|c|c|c|c|c|c|c|c|c|}
\hline $\mathbf{1 4}$ & 26.2 & 26.9 & 27.2 & 28.6 & 30.4 & 30 & 28 & 31 & 30.8 & 31.7 & 29.2 & 27 \\
\hline $\mathbf{1 5}$ & 26.2 & 27.1 & 27.4 & 28.8 & 30.7 & 30.4 & 28.3 & 31.1 & 30.9 & 31.8 & 29 & 27.2 \\
\hline $\mathbf{1 6}$ & 26.0 & 27.1 & 27.3 & 28.9 & 31 & 30.8 & 28.5 & 31 & 30.9 & 31.6 & 28.7 & 26.9 \\
\hline $\mathbf{1 7}$ & 25.3 & 26.6 & 26.7 & 28.8 & 31.2 & 31.2 & 28.5 & 30.8 & 30.8 & 31.1 & 28.1 & 25.9 \\
\hline
\end{tabular}

\section{Mimicking Plants movement in building envelop}

Plants represent one of the main players of learned biomimicry in architectural design. Plants have special features that can respond to changing environments, such as darkness, light, humidity, rainwater, fire, temperature, freezing, air movement or air quality, which make plants an inspiration of adaptive movements [37].

Plants, like buildings, lack movement and remain subject to a specific location, so they have to resist weather conditions that affect them at all times and they have special means of protection against excessive wind, drought, cold, heat and light.

Plants' reaction to their environmental changes is the basis of this research study. Several phases must be considered to enable us to apply the solutions from plant reactions into executive solutions in engineering.

This intrigued the researchers to first investigate how plants react to temperature through reactive mechanisms, then to decide whether or not such mechanisms can be used to produce adaptive architectural envelopes suitable to Egyptian climate, by evaluating the success of these alternatives in achieving thermal comfort.

The building envelope controls heat gain and loss, allows views for visual comfort, and provides natural light.

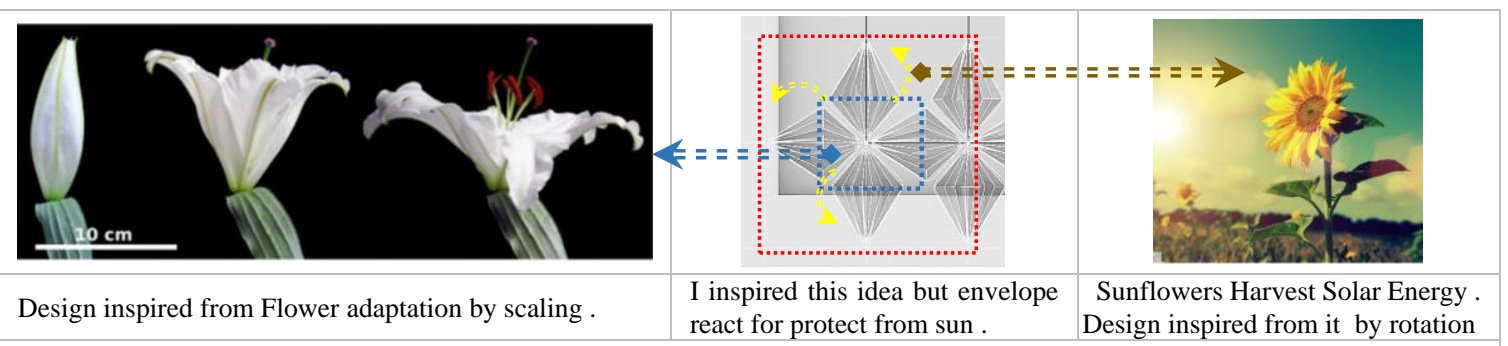

Fig. (6). Plants movement adaptation was inspired building envelope design that react with external climate for achieve indoor thermal comfort (create idea mimicking steps). Source: By Researcher.

The adaptive behavior is accomplished via the changes in the envelope configuration associated with the apparent movement of its parts, such as rotating, folding, sliding, etc., for continuing these movements, electro motors that are activated by an input from sensors and driven by outside energy input are usually the driving principle behind this type of mechanism.

\section{Translation plants mechanisms to the proposed design}

The selected organism avoiding heat gain by Mimicking Cactus \& plants movement Mechanisms:

\section{A. Mangrove flower}

The design used a biological generative system approach for pattern formalism, because it has been fascinated by Mangrove flower movement \& Cactus 
form, while designing this pattern, the researcher has set the pattern rules, parameters, and algorithms in order to mimic its shape and mechanism without making complex geometries. The Mangrove flowers have small leaves and spine that reduces the surface exposed to direct sunlight and isolate plants from gaining heat, while allowing fresh air and sun light to pass between them without heat [38].
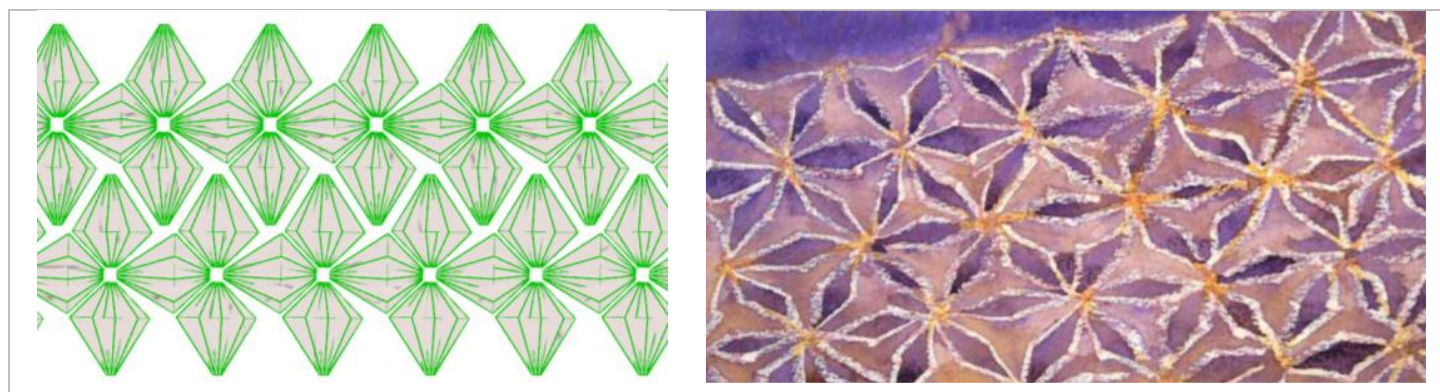

Fig. (7).The proposed design (left) inspired by Mangrove flowers pattern (right).

Source: Batanouny, K. H. (2001). Climatic Aridity in the Deserts of the Middle East.

\section{B. Cactus form}

Cacti stay cool by having ribs that provide shade and enhance heat radiation. Shading system inspired its geometry from cacti with cooling ribs. These ribs shade the surface against the scorching sun and simultaneously improve heat radiation [39].
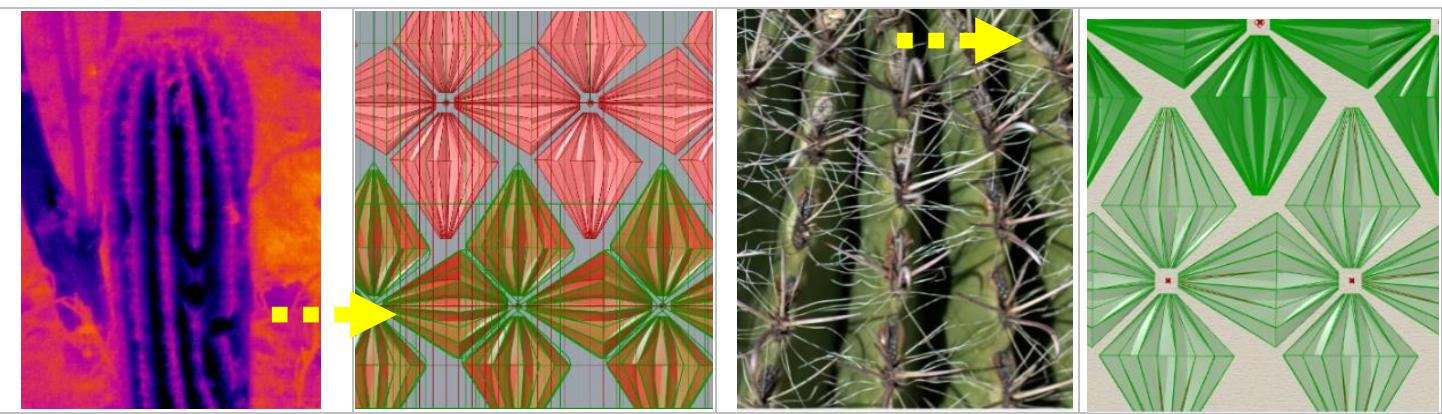

Fig. (8).Set up model in Grasshopper to evaluate biomimetic envelope for saving energy for cooling. Source: by Researcher.

\section{The Giant White Ipomoea (Morning Glory)}

The researcher inspired from Morning Glory plant rotation to react with sun and envelope shading system rotate its elements to change their shape to protect from direct intense solar radiation during the day which opening in the morning and closing in the afternoon [40].
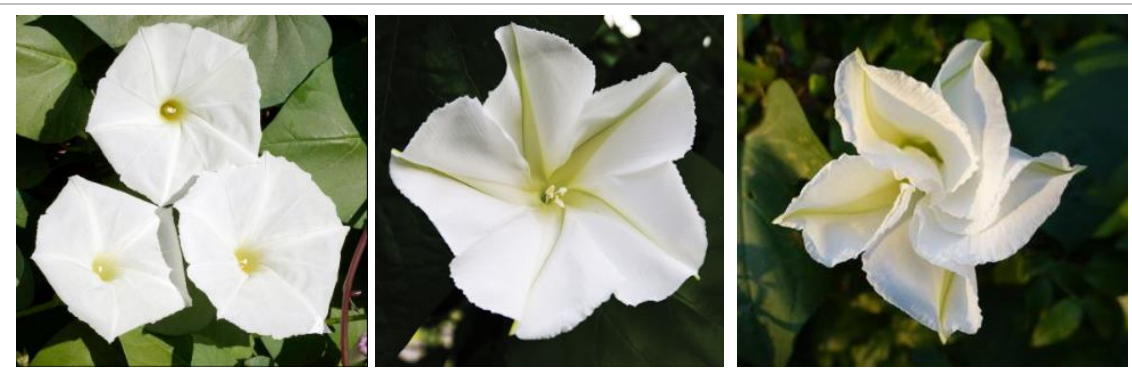

Fig. (9).The Giant White Ipomoea (Morning Glory) which opening in the morning and closing in the afternoon. Source: https://www.gardeningknowhow.com/ornamental/vines/morning-glory/ (6-3-2020). 
And simulating the movement of plants by rotating leaves which enable the plant to orient its leave away from maximum exposure to the sun [41].

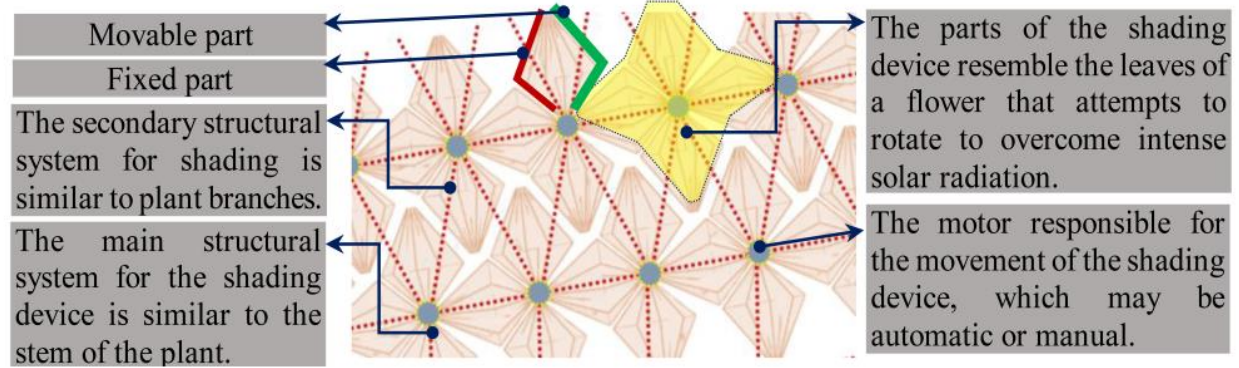

Fig. (10).Elements of the design of the Biomimetic building envelope and explains how it spins to deal with the sun. Source: by Researcher.

\section{Model description}

The designed pattern used in this model was inspired by the adaptation strategies of plants in hot, dry climates. Such plants can dynamically alter their physical shape in response to climate conditions to maintain predefined performance criteria throughout the year. These kinetic mechanisms for environmental adaptation are essential as can now be found in building skins in recent architectural design practice.

The proposed dynamic shading system is a screen comprised of rectangle units that act as individual shading devices that rotate to various angles in response to the sun's movement in order to obstruct the direct solar radiation.

Table (3) : Biomimetic design that responses to the sun in order to protect the direct solar radiation in hot times.

\begin{tabular}{|c|c|c|}
\hline & Step 2: connect between other shapes & Step 3: designing of rotating shading \\
device unit.
\end{tabular}

The shading device systems contain stainless steel supporting frames, aluminum dynamic frames, and fiberglass mesh infill. The rotating system transforms the shading screen from a seamless veil into a lattice-like pattern to provide shade or light. Each shading device comprises a series of stretched (PTFE) panels. 
PTFE Panels is a material that can stand against wind, dust, sand, and ultraviolet radiation, it also considered as a self-cleaning material and has long life expectancy of 150 years. The material has a pattern of perforations with a suitable density that enables light and air to go through it [42] .

Each unit comprises a series of stretched PTFE (poly tetra fluoro ethylene) panels repeated and is driven by a linear actuator that will progressively open and close once per day in response to a pre-programmed sequence that has been calculated to prevent direct sunlight from striking the façade and to limit direct solar gain to a maximum of 400 watts per linear meter 2 . The entire installation is protected by a variety of sensors that will open the units in the event of overcast conditions or high Winds [43] .

\section{Rotation motion mechanism of the proposed shading}

The proposed shading screen is computer-controlled to respond to optimal solar protection and light conditions. The folding shading devices are grouped into sectors and are operated through sun tracking software that controls to open and close sequence according to the sun's intensity angle. Each shading device comprises a series of stretched PTFE panels and is driven by a linear actuator. The actuator is responsible for opening and closing once per day based on a pre-programmed sequence to prevent direct solar radiation. Under overcast conditions or high wind conditions, a series of sensors integrated on the building envelope will send its logged signals to the control unit to open all units.

In this case of a shading device having different rotation angles are calculated which are $-45^{\circ},-22.5^{\circ}, 0^{\circ}, 22.5^{\circ}, 45^{\circ}$. Starting from Step 1 to step 5. Here, $-45^{\circ}$ represents the fully opened state of a shading device. As shown in Figure $4,45^{\circ}$ represents the fully closed state of a shading device.

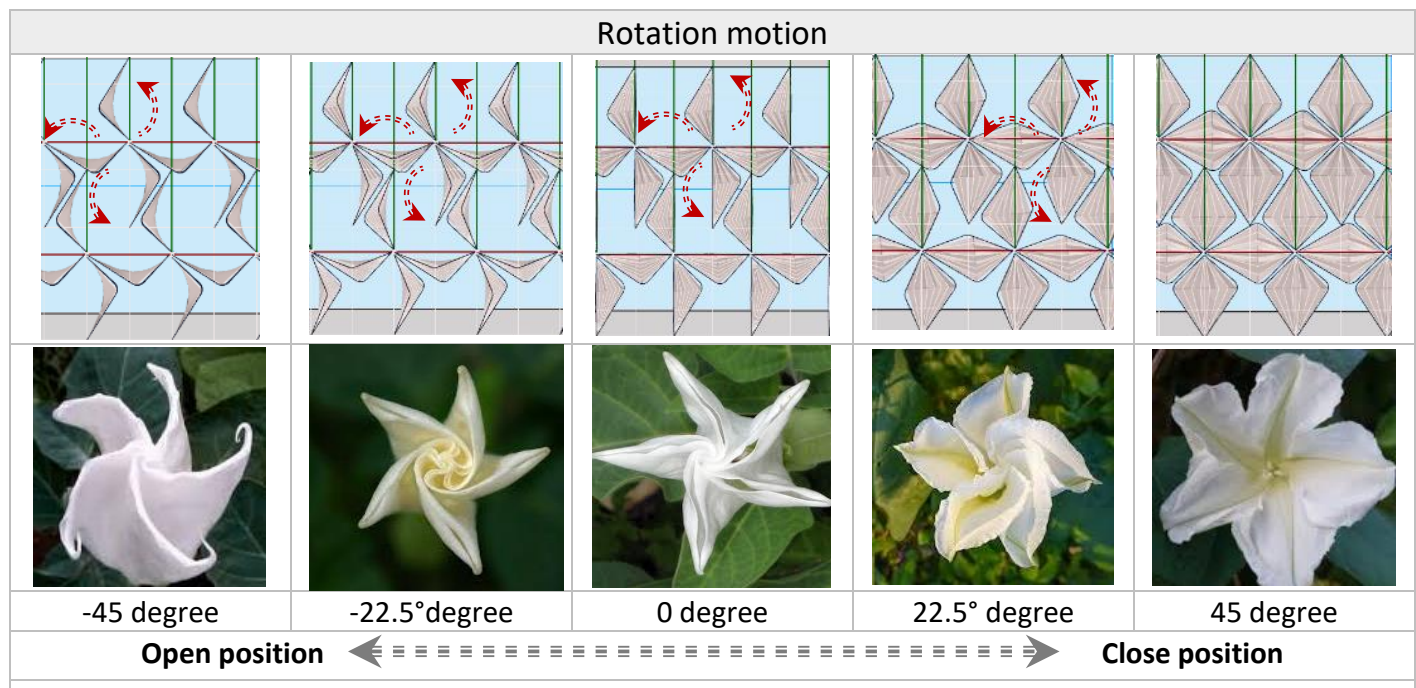

Fig. (11).Pattern transformation of the five cases for rotation motion inspired by (The Giant White Ipomoea) plants adaptation mechanism. Source: the researcher .modelling by parametric program "Grasshopper".

And it can also be provided with manual motors to suit the desire of users, due to the ease of the mechanism used to control the opening and closing of it. 


\section{Thermal Performance and Comfort Analysis}

After completing the simulation using the proposed methodology, by simulation tools and data were created. In order to analyze thermal performance of the building envelope, Zone Air Total Cooling Energy [J], were focused in the case study.

To analyze the effect of the proposed experiment on building's energy consumption, a seasonal heating/cooling analysis and a peak energy analysis for each of the heating and cooling were performed.

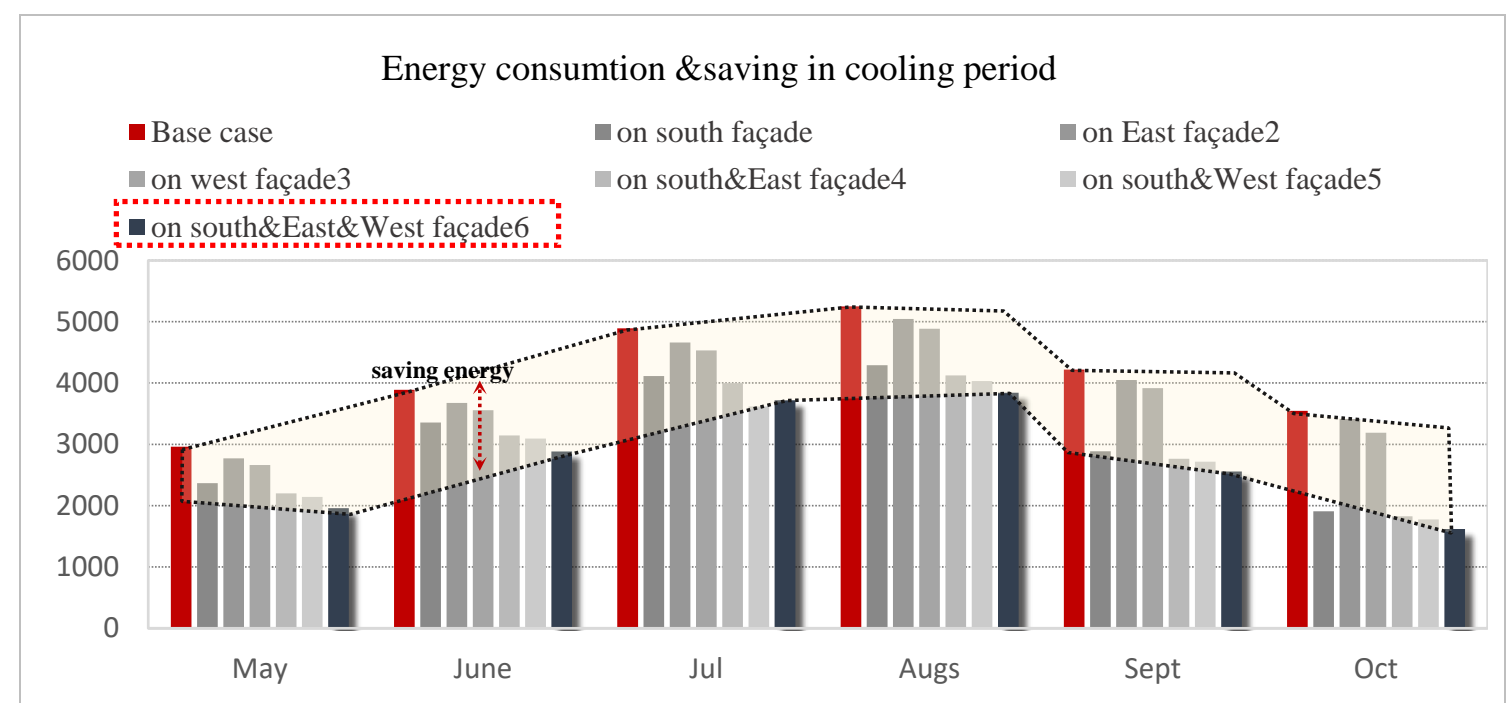

Fig.(12). Comparison between base case and Biomimetic solution simulation results that show Energy consumption \&saving during May to October (cooling period) .

Fig (13) shows annual cooling energy consumption. The figure shows that there is a reduction in cooling energy consumption across the year if applied in South \& West \&East facades $16080.4 \mathrm{kwh}$ respectively while base case $26448.3 \mathrm{kwh}$ per year that saved cooling energy by $39 \%$.

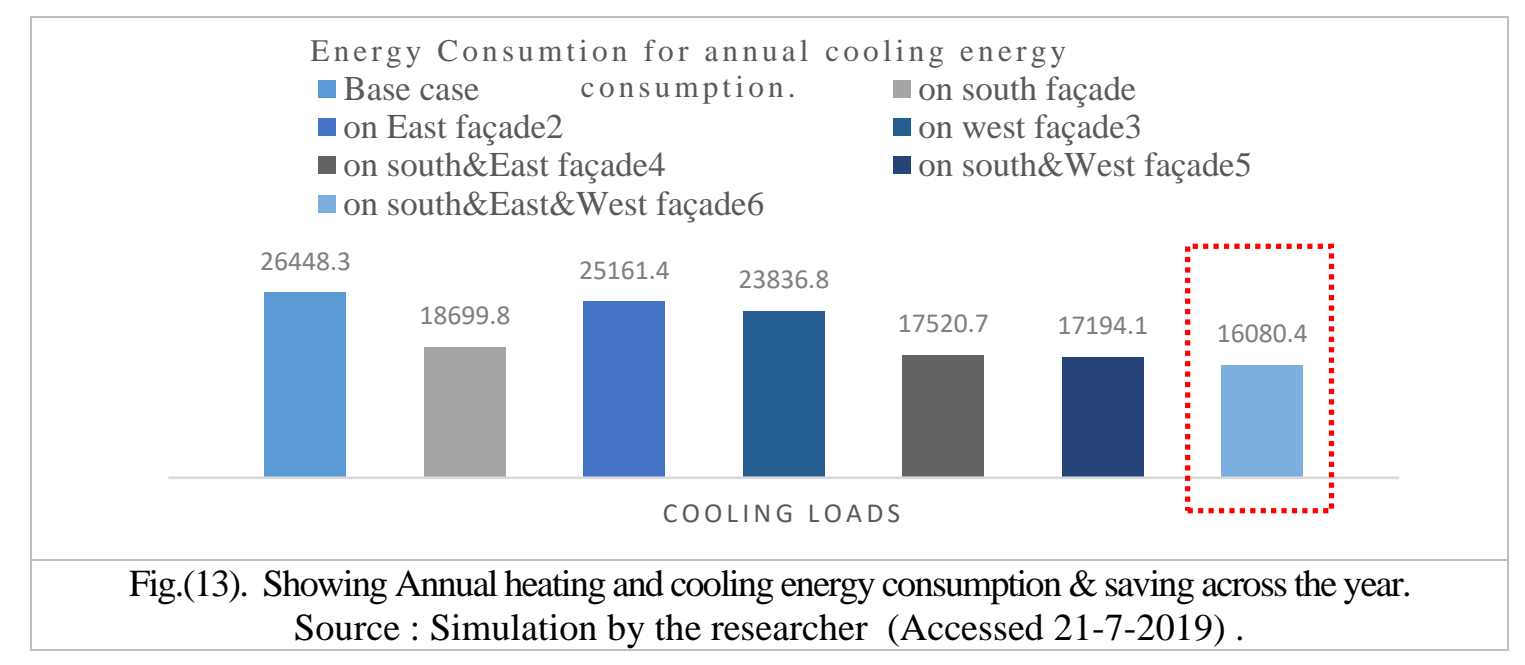




\section{Results and discussion}

The results showed that After analysis by using ladybug \& honeybee simulation programs, the results obtained showed that the overheating period begin from April to October which covers all the hour working from 8 am to $17 \mathrm{pm}$.

Simulation of the operative temperature is selected as significant indicator, the most major to express the indoor thermal comfort. The simulation indicated that applying biomimetic solution achieve a considerable reduction of heat gain, and thermal comfort, especially in summer periods, as shown in table (4), as the overheated area was reduced compared to table (2), and that the comfort hours increased by 2873 hours per year.

Table (4) illustrate the reduction in discomfort hours after applying biomimetic solution. ${ }^{\text {(by researcher simulation). }}$

\begin{tabular}{|c|c|c|c|c|c|c|c|c|c|c|c|c|}
\hline \multicolumn{10}{|c|}{ Operative temp the most major to express the indoor thermal comfort } \\
\hline H & Jan & Feb & Mar & $\begin{array}{c}\text { Apri } \\
\text { l }\end{array}$ & May & Jun & Jule & Aug & Sep & Oct & Nov & Des \\
\hline $\mathbf{8}$ & 17.9 & 19.4 & 20.1 & 21.0 & 24.7 & 24.6 & 25.5 & 25.2 & 24.4 & 24.3 & 20.4 & 19.5 \\
\hline $\mathbf{9}$ & 18.0 & 19.4 & 20.1 & 20.9 & 24.8 & 24.6 & 25.5 & 25.1 & 24.4 & 24.2 & 21.3 & 19.5 \\
\hline $\mathbf{1 0}$ & 18.1 & 19.4 & 20.2 & 21.2 & 25.0 & 24.6 & 25.7 & 25.2 & 24.5 & 24.3 & 21.8 & 19.5 \\
\hline $\mathbf{1 1}$ & 18.3 & 19.5 & 20.6 & 21.7 & 25.3 & 24.8 & 25.8 & 25.4 & 24.7 & 24.4 & 22.1 & 19.7 \\
\hline $\mathbf{1 2}$ & 18.4 & 19.9 & 21.2 & 22.2 & 25.6 & 25.0 & 26.1 & 25.7 & 24.9 & 24.7 & 22.5 & 19.9 \\
\hline $\mathbf{1 3}$ & 18.5 & 20.3 & 21.8 & 22.9 & 26.0 & 25.3 & 26.3 & 25.9 & 25.2 & 25.0 & 22.8 & 20.2 \\
\hline $\mathbf{1 4}$ & 18.6 & 21.1 & 22.4 & 23.8 & 26.3 & 25.8 & 26.6 & 26.3 & 25.5 & 25.3 & 23.1 & 20.9 \\
\hline $\mathbf{1 5}$ & 18.8 & 21.9 & 22.6 & 24.7 & 26.6 & 26.1 & 27.0 & 26.6 & 25.8 & 25.7 & 23.4 & 21.2 \\
\hline $\mathbf{1 6}$ & 18.9 & 22.6 & 23.1 & 25.5 & 26.9 & 26.4 & 27.3 & 26.9 & 26.1 & 26.0 & 23.7 & 21.8 \\
\hline $\mathbf{1 7}$ & 19.0 & 22.9 & 23.6 & 26.2 & 27.1 & 26.8 & 27.5 & 27.2 & 26.3 & 26.2 & 23.9 & 22.4 \\
\hline
\end{tabular}

\section{Conclusion}

Plants represent one of the main players of learned biomimicry in architectural design. Plants have several unique features that help them adapt to improper weather condition of humidity, temperature, darkness, light, rainwater, fire, air movement or air quality, freezing, which make plants an inspiration of adaptive movements.

The current study succeeded in developing a conceptual biomimetic model of adaptive envelop as a way of protection from excessive heat gain by building's skins. This new approach can help in enhancing cooling and achieving thermal comfort in buildings located in hot climate such as in Cairo. This convert conventional envelope into a dynamic envelop that respond to external environment to thermo regulate its temperature.

The proposed system reduced glare, improved daylight penetration, less reliance on artificial lighting, and achieved over $50 \%$ reduction in solar gain, which results in a reduction of $\mathrm{CO} 2$ emissions and achieving indoor thermal comfort . 
References

[1] Ürge-Vorsatz, D., Cabeza, L. F., Serrano, S., Barreneche, C., \& Petrichenko, K. (2015). Heating and cooling energy trends and drivers in buildings. Renewable and Sustainable Energy Reviews, 41, 85-98..

[2] Omrany, H., Ghaffarianhoseini, A., Ghaffarianhoseini, A., Raahemifar, K., \& Tookey, J. (2016). Application of passive wall systems for improving the energy efficiency in buildings: A comprehensive review. Renewable and sustainable energy reviews, 62 ,

[3] Azari, R. (2019). Life Cycle Energy Consumption of Buildings; Embodied+ Operational. In Sustainable Construction Technologies (pp. 123-144). Butterworth-Heinemann..

[4] Wang, Y., Kuckelkorn, J., Zhao, F. Y., Spliethoff, H., \& Lang, W. (2017). A state of art of review on interactions between energy performance and indoor environment quality in Passive House buildings. Renewable and Sustainable Energy Reviews, 72, 130.

[5] [9] Barbosa, S., \& Ip, K. (2014). Perspectives of double skin façades for naturally ventilated buildings: A review. Renewable and Sustainable Energy Reviews, 40, 1019-1029..

[6] Liu, L., Li, H., Lazzaretto, A., Manente, G., Tong, C., Liu, Q., \& Li, N. (2017). The development history and prospects of biomass-based insulation materials for buildings. Renewable and Sustainable Energy Reviews, 69, 912-932.

[7] López, M., Rubio, R., Martín, S., \& Croxford, B. (2017). How plants inspire façades. From plants to architecture: Biomimetic principles for the development of adaptive architectural envelopes. Renewable and Sustainable Energy Reviews, 67, 692-703..

[8] Ali, G., Abbas, S., \& Qamer, F. M. (2013). How effectively low carbon society development models contribute to climate change mitigation and adaptation action plans in Asia. Renewable and Sustainable Energy Reviews, 26, 632-638.

[9] Mead, S. P. (2008). Biomimetics: Biologically Inspired Ideas for Construction. International Journal of Construction Education \& Research, USA..

[10] Baumeister, D., Tocke, R., Dwyer, J., Ritter, S., \& Benyus, J. (2012). Biomimicry resource handbook. A seed..

[11] Lipholt, N. R. W. (2019). Biomimicry-Where Nature is Changing Innovation (Bachelor's thesis, University of Twente).. 
[12] Scott, W., \& Vare, P. (2018). Biomimicry. The World We'll Leave Behind, 222(225), 4 ..

[13] "Goss, J. (2009). Biomimicry: Looking to nature for design solutions. Corcoran College of Art and Design.".

[14] "Oguntona, O. A., \& Aigbavboa, C. O. (2017). Biomimicry principles as evaluation criteria of sustainability in the construction industry. Energy Procedia, 142, 2491-2497.".

[15] Guild, B. (2007). Innovation inspired by nature work book. Biomimicry Guild..

[16] Benyus, J. (1997). Biomimicry - innovation inspired by nature. New York: Harper Collins Publishers.

[17] Othmani, N. I., Yunos, M. Y. M., Ismail, N. A., \& Rahman, K. A. A. A. (2018) . Review on Biomimicry Levels. American Journal of Humanities and Social Sciences Research (AJHSSR) e-ISSN : 2378-703X , 2 (8) , 5558 ..

[18] Arslan, G. Y. (2014). Biomimetic architecture a new interdisciplinary approach to architecture. ALAM CIPTA, International Journal of Sustainable Tropical Design Research and Practice, 7(2), 29-36..

[19] Fox, M. (Ed.). (2016). Interactive architecture: adaptive world. Chronicle Books..

[20] Lollini, R., Danza, L., \& Meroni, I. (2010). Energy efficiency of a dynamic glazing system. Solar Energy, 84(4), 526-537..

[21] Fox, M. A. (2003). Kinetic architectural systems design. Transportable environments, 2, 163-186..

[22] Elkhatieb, M., \& Sharples, S. (2016). Climate Adaptive Building Shells for Office Buildings in Egypt: A Parametric and Algorithmic Daylight Tool. SBE16 Dubai, Dubai-UAE..

[23] Kirkegaard, P., \& Foged, I. W. (2010). Development and evaluation of a responsive building envelope. In International Adaptive Architecture Conference (pp. 1-9)..

[24] Elkhatieb, M. A. (2017). A Performance-driven Design Model of Territorial Adaptive Building Skin (TABS) for Daylighting Performance Optimisation in Office Buildings in Egypt (Doctoral dissertation, University of Liverpool)..

[25] Del Grosso, A. E., \& Basso, P. (2010). Adaptive building skin structures. Smart Materials and Structures, 19(12), 124011. 
[26] Loonen, R. C. G. M., Trčka, M., Cóstola, D., \& Hensen, J. L. M. (2010). Performance simulation of climate adaptive building shells-Smart Energy Glass as a case study. Proceedings of SSB, 1-19..

[27] Badarnah, L., \& Knaack, U. (2008). Organizational features in leaves for application in shading systems for building envelopes. WIT Trans. Ecol. Environ, 114, 87-96.

[28] Alexander Matthias Jacobson , ladybug-tools/honeybee-legacy , https://github.com/ladybug-tools/honeybee-legacy/wiki (accessed 1-12020).

[29] Roudsari, M. S., Pak, M., \& Smith, A. (2013, August). Ladybug: a parametric environmental plugin for grasshopper to help designers create an environmentally-conscious design. In Proceedings of the 13th international IBPSA conference held in Lyon, France A.

[30] https://en.climate-data.org/africa/egypt/cairo-governorate/cairo3392/\#climate-table (Accessed 29-12-2019).

[31] Lee, J., \& Strand, R. K. (2001). An analysis of the effect of the building envelope on thermal comfort using the EnergyPlus program..

[32] Hwang, R. L., \& Shu, S. Y. (2011). Building envelope regulations on thermal comfort in glass facade buildings and energy-saving potential for PMV-based comfort control. Building and Environment, 46(4), 824-834..

[33] Standard, A. S. H. R. A. E. (2010). Standard 55-2010, Thermal environmental conditions for human occupancy. American Society of Heating, Refrigerating and Air Conditioning Engineers..

[34] Al-Tamimi, N. A. M., \& Fadzilb, S. F. S. (2010). Experimental and Simulation Study for Thermal Performance Analysis in Residential Buildings in Hot-Humid Climate (Comparative Study). Journal of Science and Technology, 15 .

[35] Rajapaksha, I., Nagai, H., \& Okumiya, M. (2003). A ventilated courtyard as a passive cooling strategy in the warm humid tropics. Renewable Energy, 28(11), 1755-1778. .

[36] Standard, A. S. H. R. A. E. (2010). Standard 55-2010, Thermal environmental conditions for human occupancy. American Society of Heating, Refrigerating and Air Conditioning Engineers..

[37] Al-Obaidi, K. M., Ismail, M. A., Hussein, H., \& Rahman, A. M. A. (2017). Biomimetic building skins: An adaptive approach. Renewable and Sustainable Energy Reviews, 79, 1472-1491.. 
[38] Batanouny, K. H. (2001). Climatic Aridity in the Deserts of the Middle East..

[39] Shape shades and enhances heat radiation Edit title, https://asknature.org/strategy/shape-shades-and-enhances-heat-radiation/ (accessed 12-1-2020)..

[40] Growing Morning Glories: How To Grow Morning Glory Flowers https://www.gardeningknowhow.com/ornamental/vines/morningglory/growing-morning-glories.htm..

[41] Mahmoud, E. L. G. H. A. W. A. B. Y. (2010). Biomimicry: a New Approach to Enhance the Efficiency of Natural Ventilation Systems in Hot Climate. In International seminar arquitectonics network, Architecture and research, Barcelona..

[42] Pohl, G. (Ed.). (2010). Textiles, polymers and composites for buildings. Elsevier..

[43] Alkhayyat, J. (2013). Design strategy for adaptive kinetic patterns: creating a generative design for dynamic solar shading systems. Architecture, University of Salford.. 